\title{
Yıkama süresinin elastomerik ölçü materyallerinin Islanabilirliği üzerine etkisi: in vitro çalışma
}

\author{
Özlem Acar, ${ }^{*}$ Selim Erkut \\ Protetik Diş Tedavisi Anabilim Dalı, Başkent Üniversitesi Diş \\ Hekimliği Fakültesi, Ankara, Türkiye
}

\section{Özet}

AMAÇ: Farklı yıkama sürelerinin polimerize olmuş elastomerik ölçü materyallerinin ıslanabilirlik değerleri üzerindeki etkisini değerlendirmektir.

Gereç Ve Yöntem: Panasil Contact Plus (PCP), Panasil Contact Sürfaktansız Deney Materyali (PCNS), Panasil Initial Contact (PIC), Express (EXP) ve Impregum (IMP) ölçü materyalleri değerlendirildi. Ölçü yüzeylerin ıslanabilirliği, 10 sn, 15 sn ve 20 sn sürelerince su ile yıkanan örnekler üzerinde temas açısı ölçüm cihazı kullanılarak ölçüldü $(n=7)$. Ölçüm süresi 60 sn idi. Kontrol grubunda yıkama yapılmadı. Ölçümler 5 noktada yapıldı $(0,6,15,30$ ve 60 . saniyeler). Kruskal Wallis testi ve tüm olası çoklu karşılaştırmalar için Conover Çoklu Karşılaştırma testi kullanıldı. Tip I hatayı kontrol etmek amacıyla Bonferroni düzeltmesi yapıldı ( $p<0.002)$.

BULGULAR: Farklı yıkama sürelerinin (10 sn, 15 sn ve 20 sn) PCP, PIC ve EXP ölçü materyallerinin ıslanabilirlik değerlerinde istatistiksel olarak azalmaya neden olduğu $(p<0.002)$, IMP ve PCNS ölçü materyallerinde ise etkili olmadığı görüldü ( $p>0.002$ )

SoNuç: Yıkama işleminin sürfaktan içeren polivinilsiloksan ölçü materyallerinin ıslanabilirliğinin azalmasına neden olduğu, sürfaktan içermeyen polivinilsiloksan ölçü materyali ve polieter ölçü materyalinde ise etkili olmadığı sonucuna ulaşıılı.

AnAHTAR Kelimeler: Dental ölçü materyalleri; ıslanabilirlik; polimerizasyon

KaynaK GöStermek İçin: Acar Ö, Erkut S. Yıkama süresinin elastomerik ölçü materyallerinin Islanabilirliği üzerine etkisi: in vitro çalışma. Acta Odontol Turc 2016;33(1):24-9

Ерітӧв: Özgül Karacaer, Gazi Üniversitesi, Ankara, Türkiye

YAYIN HAKKI: (c) 2016 Acar ve Erkut. Bu eserin yayın hakk Creative Commons Attribution License ile ruhsatlandırılmıştır Sınırsız kullanım, dağıtım ve her türlü ortamda çoğaltım, yazarlar ve kaynağın belirtilmesi kaydıyla serbesttir.

[Abstract in English is at the end of the manuscript]

Makale gönderiliş tarihi: 24 Mart 2015; Yayına kabul tarihi: 19 Ekim 2015 *iletișim: Özlem Acar, Protetik Diș Tedavisi Anabilim Dalı, Başkent Üniversitesi Diş Hekimliği Fakültesi, Ankara, Türkiye;

e-posta: zlemacr@gmail.com
Giriş

Islanabilirlik, bir sıvının katı bir yüzey üzerine yayılabilme kabiliyetini ifade eder ve direkt yöntemlerle ölçülebilir. Katı materyal ile sıvı arasında gözlenen temas açısı katı yüzeyin yapısı ile sıvının enerjisine bağlıdır ve yüzey gerilimi olarak ifade edilir $(\mathrm{mN} / \mathrm{m}=\mathrm{dynes} / \mathrm{cm})$. Ölçü materyalleri söz konusu olduğunda; temas açısı ölçümü geleneksel yöntemlerle, su ya da doymuş kalsiyum sülfat solüsyonu ile 'sessile drop' yöntemi kullanılarak yapılmaktadır. ${ }^{1,2}$ Yüksek temas açısı $\left(>90^{\circ}\right)$ zayıf ıslanabilirliğin bir göstergesidir, temas açısı azaldıkça ıslanabilirlik artmaktadır. Sıfır derece $\left(0^{\circ}\right)$ yüzeyin mükemmel ıslanabilirliğini göstermektedir. ${ }^{3} \mathrm{O}^{\prime}$ Brein'a $^{3}$ göre bir ölçü materyalinin ıslanabilirlik özelliği değerlendirilirken, ağız içerisinde yumuşak ve sert dokular üzerindeki akma kabiliyeti ile materyalin alçı ile ıslanabilme özelliği birbirinden ayrılmalıdır.

Polivinilsiloksanlar (PVS) üstün boyutsal stabilite ve detay kopyalama özellikleriyle sıklıkla tercih edilen ölçü materyalleridir, ancak apolar kimyasal yapıları nedeniyle yapısal olarak hidrofobiktir. ${ }^{4-6}$ Hidrofobik yapı nemli oral dokularla ve alçı bazlı day materyallerinin su içeren solüsyonlarıyla ıslanabilirliğini azaltmaktadır. ${ }^{7}$ Azalan ıslanabilirlik değerleri alçı model üzerinde hava kabarcıkları ve boşluklarla sonuçlanmaktadır. ${ }^{8,9}$ Oysa restorasyonun başarısı ölçü ve dayın hava kabarcı̆̆ı, boşluk, düzensizlik gibi hataları içermemesiyle doğru orantılı olarak artmaktadır. ${ }^{10}$

PVS ölçü materyallerinin ıslanabilirlik özelliği üretici firmalar tarafından sürfaktan ilave edilmesi ile iyileștirilmiştir. ${ }^{1,9,11,12}$ Bunlar genellikle nonylphenoxypoly (ethyleneoxy) ethanol homologu non-iyonik sürfaktanlardır. ${ }^{13}$ Sürfaktan polimerize olmuş materyalin yüzey enerjisini arttırmaktadır. ${ }^{14}$ Sürfaktanın hidrofilisitesi yanında yüzeyde bulunan sürfaktan konsantrasyonu yüzey aktivasyonunda oldukça önemlidir. ${ }^{15}$ Polimerizasyonu tamamlanan ölçü materyalinde yüzey yönünde sürfaktan hareketi gözlenebilmektedir. Bu hareket, sürfaktan molekülleri ile polimer zincirleri arasındaki bağın kuvveti ile ilişkilendirilmektedir. ${ }^{16}$ Kanehira ve arkadaşlarına ${ }^{17}$ göre polimerizasyon sonrası kuru yüzeyli PVS ölçü materyallerinin temas açısı değerinin aşamalı olarak azalması, kritik seviyedeki miktarın daha derin ta- 
bakalardan yüzeye diffüze olması sonucunda su damlası içerisindeki sürfaktan içeriğinin ayrışması ile açıklanabilir.

Geleneksel olarak tüm ölçülerin alçı model elde edilmeden önce dezenfekte edilmeleri gerekmektedir. Ancak PVS ölçü materyallerinin kimyasal dezenfeksiyonu, ıslanabilirlik özelliğinin azalmasına neden olabileceği gibi, ${ }^{18,19}$ kullanılan ölçü materyalinin markası ve kimyasal dezenfeksiyon yöntemine bağlı olarak (fenol, iyodofor, sodyum hipoklorit, glutaraldehit) Islanabilirliğin değişmemesine ya da artmasına da neden olabilir. ${ }^{19}$ Diğer bir yöntem olan mikrodalga dezenfeksiyonu ise ölçüye ${ }^{20}$ ya da alçı modele ${ }^{21,22}$ uygulanabilir. Alçı modelin mikrodalga ile dezenfeksiyonunun enfeksiyon kontrol kuralları kılavuzuna uygun şekilde yüksek seviyede dezenfeksiyon sağladığı bildirilmiştir. ${ }^{21,22}$ Choi ve ark. ${ }^{20}$ bu yöntemin materyalin ıslanabilirlik gibi fiziksel özelliklerini değiştirmediğini göstermişlerdir. Ancak mikrodalga dezenfeksiyonu öncesinde ölçünün ağız sıvılarından arındırılmaları için su ile temizlenmesi halen bir gerekliliktir. Yıkama işlemi ise yüzeyde serbest konumdaki sürfaktanın uzaklaşmasına, ölçü yüzeyinin daha hidrofobik hale gelmesine neden olabilir. Yapılan literatür araştırmasında PVS ölçü materyallerinin farklı yıkama sürelerini takiben ıslanabilirlik özelliklerinin değerlendirildiği bir çalışmaya rastlanmamıştır. Bu çalışmanın amacı farklı yıkama zamanlarının PVS ölçü materyallerinin ıslanabilirlik özelliğini etkileyip etkilemediğini araştırmaktır. Çalışmanın hipotezi 'farklı yıkama sürelerinin ölçü materyallerinin ıslanabilirliği üzerinde bir etkisi bulunmamaktadır' olarak kurulmuştur.

\section{Gereç ve Yöntem}

Bu çalışmada 'light body' (akıcı kıvam) viskozitesinde 5 farklı ölçü materyali değerlendirildi. Bunlar; Panasil Contact Plus (PCP; Kettenbach GmbH \& Co KG, Eschenburg, Almanya), Panasil Contact Plus Non-Surfactant [Sürfaktansız Deney Materyali; PCNS; Kettenbach $\mathrm{GmbH} \&$ Co KG), Panasil Initial Contact (PIC; Kettenbach $\mathrm{GmbH}$ \& Co KG), Express (EXP; 3M ESPE AG, Seefeld, Almanya) ve Impregum (IMP; 3M ESPE AG) ölçü materyalleridir.

Çalışmamızda değerlendirilen 5 farklı ölçü materyalinin her birinden 7 adet örnek hazırlandı. Örneklerin hazırlanması sırasında standart kalınlık oluşturmak amacıyla $10 \times 8 \mathrm{~cm}$ boyutlarında iki cam levha ve 1 kg'lik sabit yük kullanıldı. Cam levhalar önce sıvı deterjan ile ardından etil alkol emdirilmiş kağıt peçete ile temizlendi. İki pat halinde bulunan ölçü materyalinin homojen karışımını oluşturabilmek için kartuşlu tabanca sistemi tercih edildi. Her bir örnek hazırlanırken, karışımın homojen olmayan 2 cm'lik ilk kısmı kullanılmadı. Ölçü materyali iki cam levha arasına yerleştirildi, 1 kg yük altında, 15 dakika boyunca ve sabit laboratuar ko- şullarında polimerizasyonun tamamlanması sağlandı. Örnekler her bir ölçü materyali için, 10 sn, 15 sn veya 20 sn yıkama ve yıkama yapılmayan kontrol grubu olmak üzere 4 alt gruba ayrıldı $(n=7)$. Yıkama işlemi, standart dental ünitede belirtilen sürelerde yapıldı. Yıkama sonrası örnekler hafif hava basıncı ile kurutuldu. Hazırlanan örnekler yüzey kontaminasyonunu önlemek amacıyla temas açısı ölçümlerine kadar alüminyum folyolara sarılarak muhafaza edildi.

Temas açısı ölçümleri, 'sessile drop' tekniği kullanılarak OCA 30 (Data Physics Instruments GmbH, Filderstadt, Almanya) temas açısı ölçüm cihazı ile yapıldı. Damlanın yüzeye temasını takiben temas açısındaki değişikliklerin zamana bağlı olarak değerlendirilmesi amaçlandı. Ölçüme, 0 sn'de başlandı ve 60 sn boyunca devam edildi. Belirlenen 5 zaman noktasındaki veriler istatistiksel değerlendirmeye alındı; bu noktalar 0, 6, 15, 30 ve 60. sn'dir. Temas açısı ölçümüne dair tipik bir örnek kaydı Şekil 1'de gösterildi.

Chai and Yeung ${ }^{13}$ yaptıkları pilot çalışmada temas açısındaki değişimlerin 30 saniyelik zaman diliminde oldukça küçük olduğunu bildirmişler ve alçının bu zaman aralığında halen müdahale edilebilir olduğunu göstermişlerdir. Bu nedenle çalışmamızda 30. sn ölçümü değerlendirme noktaları içerisine dahil edildi. Kullanılan yazılım ile ölçümün, su damlası yüzeye temas etmeden başlatılması sağlandı. Böylece damlanın yüzeye ilk temas ettiği an elde edilen değer, 0 sn değeri olarak ölçüldü.

Islanabilirlik değerlendirmesinde verilerin analizi SPSS 11.5 (SPSS Inc., Chicago, IL, ABD) paket programında yapıldı. Kullanılacak test istatistiğine karar vermeden önce ıslanabilirlik ölçümlerinin dağılımının normal dağılıma uygun dağılıp dağılmadığı Kolmogorov Smirnov testiyle varyansların homojen olup olmadığı ise Levene testiyle araştırıldı. Yukarıdaki parametrik test istatistiği varsayımları sağlanmadığı için bu çalışmada non-parametrik test istatistiği olan Kruskal Wallis testi kullanıldı. Kruskal Wallis testinin önemli bulunduğu tüm sonuçlar için farka neden olan durumları tespit etmek amacıyla çoklu karşılaştırmalar yapıldı. Tüm olası çoklu karşılaştırmalar için Conover Çoklu Karşılaştırma testi kullanıldı. Tip I hatayı kontrol etmek amacıyla Bonferroni düzeltmesi yapıldı $(p<0.002)$.

\section{Bulgular}

Çalışmamızda 4 farklı PVS ve 1 adet polieter olmak üzere 5 farklı marka elastomerik ölçü materyalinin farklı yıkama sürelerini takiben gösterdikleri ıslanabilirlik değişimleri incelendi. Yapılan çoklu karşılaştırma testlerinin sonuçları her bir ölçü materyali için aşağıda verildi.

PCP ölçü materyali grubunda, temas açısı değerlerinin yıkama yapılmadığında $89.97^{\circ}$ ile başlayıp $53.15^{\circ}$ ile sonlandığı görüldü. Ölçü materyalinin yıkama işlemi ile 


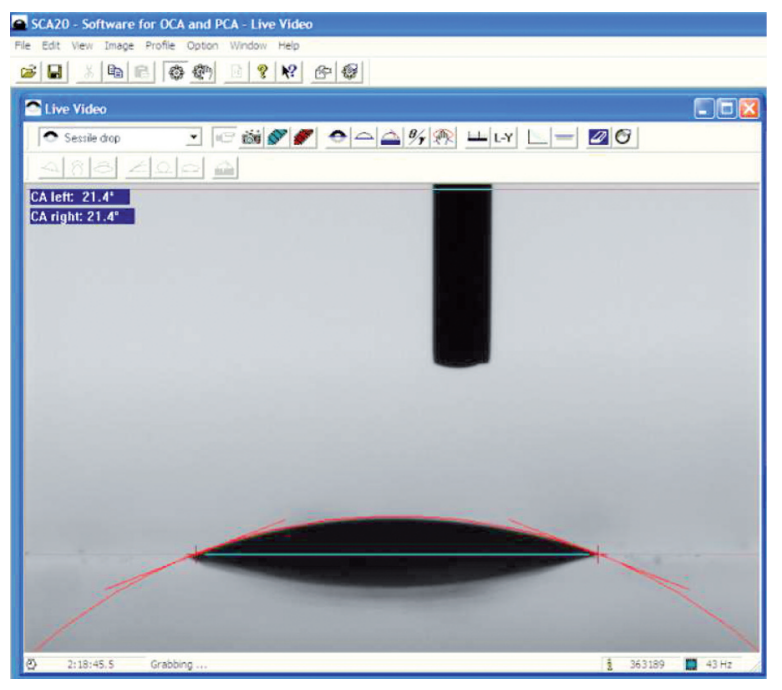

Şekil 1. Temas açısı ölçümüne ait tipik bir örnek kaydı

değişim gösteren temas açısı değerleri Şekil 2'de gösterildi. Bu grupta farkı sürelerde yıkama yapılmasının, tüm değerlendirme zamanları için ıslanabilirliğin azalmasına neden olduğu gözlendi $(p<0.002)$. On sn yıkama ile 15 sn yıkama süreleri arasındaki fark değerlendirildiğinde ilk ölçüm anında (0 sn) fark gözlenirken $(p<0.002)$, diğer değerlendirme zamanlarında fark bulunmadı ( $p>0.002)$. On sn yıkama ile 20 sn yıkama süreleri arasındaki fark değerlendirildiğinde ise, başlangıç ve bitim zamanlarında fark gözlenmezken sadece 15. sn ve 30. sn ölçümlerinde fark bulundu $(p<0.002)$. On beş sn yıkama ile 20 sn yıkama süreleri değerlendirildiğinde yine başlangıç ve bitim zamanlarında fark gözlenmezken, sadece 15 . sn ve 30 . sn ölçümlerinde fark bulundu $(p<0.002)$. Alçının yayılması ile ilişkilendirilen kritik 30. sn ölçümünde ise yıkama yapıımasının tüm yıkama süreleri için ıslanabilirliği azalttığı gözlendi ( $p<0.002)$. Yine bu kritik değerde, 20 sn yıkama diğer tüm yıkama sürelerine kıyasla ıslanabilirliğin azalmasına neden olurken $(p<0.002), 10$ sn yıkama ile $15 \mathrm{sn}$ yıkama yapılmasının farka neden olmadığı görüldü $(p=0.7164)$. Altmış sn değerinde ise yıkama yapılması tüm süreler için ıslanabilirliğin azalmasına neden olurken $(p<0.002), 10$ sn, 15 sn ve 20 sn yıkama süreleri arasında sırasıyla ikili karşılaştırmalarda fark gözlenmedi $(p=0.1077, p=0.0950, p=0.9473)$.

PCNS ölçü materyali grubunda, temas açısı değerlerinin yıkama yapılmadığı takdirde, $92.97^{\circ}$ ile başlayıp $92.07^{\circ}$ ile sonlandığı gözlendi. Ölçü materyalinin yıkama işlemi ile değişim gösteren temas açısı değerleri Şekil 3 'te gösterildi. Yine bu grupta belirtilen sürelerin herhangi biri için yıkama yapılması, yine belirtilen değerlendirme zamanlarının herhangi biri için istatistiksel farklılığa neden olmadı ( $p>0.002$ ). Sürfaktan içerikleri dışında kimyasal yapıları benzer olan PCP ve PCNS ölçü grupları karşılaştırılacak olursa, yıkama yapılmaması durumunda iki ölçü materyalinin 0 sn, 6 sn, 15 sn, 30 sn, ve 60. sn'lerde temas açısı değerleri sırasıyla şöyledir: 89.97/92.75, 90.31/92.68, 75.64/92.37, 64.11/ 91.88 ve 53.15/92.07. PCP ölçü materyalinin temas açısı değeri azalırken, PCNS ölçü materyalinin temas açısı değerinin sabit kaldığı gözlendi. İki ölçü materyalinin temas açısı değerlerinde farklılık gözlense de, iki grup arasında sadece 60. sn ölçümünde istatistiksel farklılık bulundu $(p<0.002)$. İki ölçü materyalinin benzer yıkama koşullarında ıslanabilirlik değerleri arasında istatistiksel farklılık bulunmadı ( $p>0.002$ ).

PIC ölçü materyali grubunda; temas açısı değerlerinin yıkama yapılmadığı takdirde, $52.14^{\circ}$ ile başlayıp $0.35^{\circ}$ ile sonlandığı görüldü. Bu değerlerin IMP ölçü materyali hariç, diğer tüm ölçü materyallerinden istatistiksel olarak farklı olduğu gözlendi $(p<0.002)$. Ölçü materyalinin yıkama işlemi ile değişim gösteren temas açıSı değerleri Şekil 4'te gösterildi. PIC grubunda yıkama yapılması, genel anlamda ıslanabilirliğin azalmasına neden olurken $(p<0.002), 6$. sn ölçümlerinde fark gözlenmedi ( $p>0.002)$. Benzer şekilde yıkama yapılmayan grup ile 5 sn yıkama yapılan grup arasında başlangıç ölçümünde de fark gözlenmedi ( $p>0.002)$. On sn

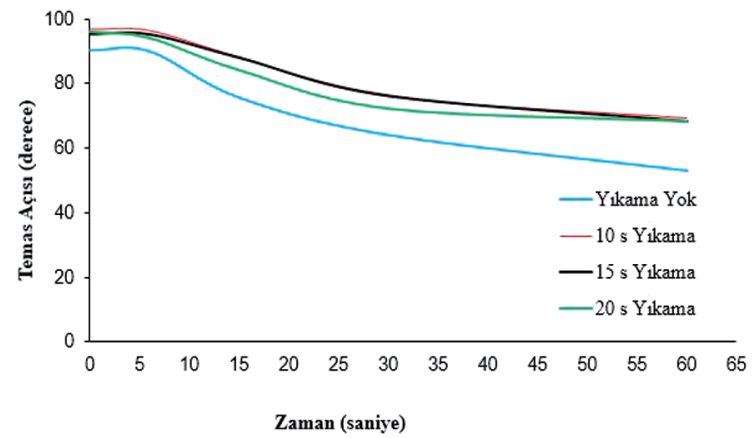

Şekil 2. Polimerizasyonu tamamlanmış PCP ölçü materyalinin yıkama yapılmadan, 10 sn, 15 sn ve 20 sn yıkama sonrası zamana bağlı göstermiş olduğu temas açısı değişimi

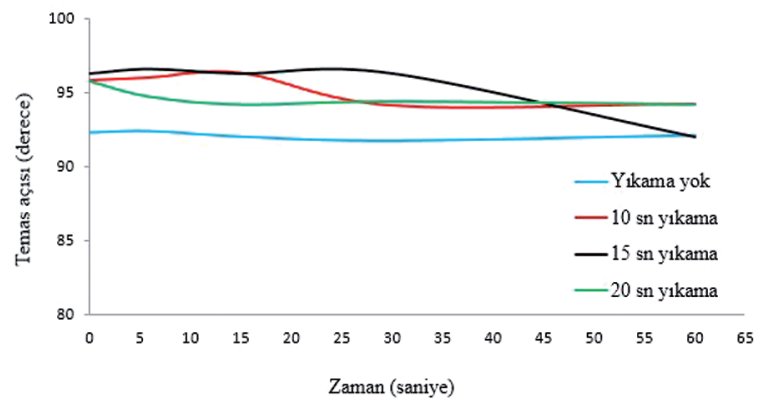

Şekil 3. Polimerizasyonu tamamlanmış PCNS ölçü materyalinin yıkama yapılmadan, 10 sn, 15 sn ve 20 sn yıkama sonrası zamana bağlı göstermiş olduğu temas açısı değişimi 


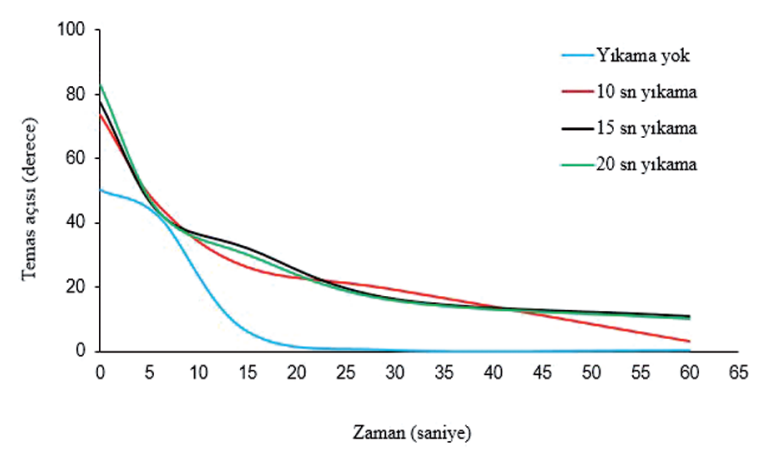

Şekil 4. Polimerizasyonu tamamlanmış PIC ölçü materyalinin yıkama yapılmadan, 10 sn, 15 sn ve 20 sn yıkama sonrası zamana bağlı göstermiş olduğu temas açısı değişimi

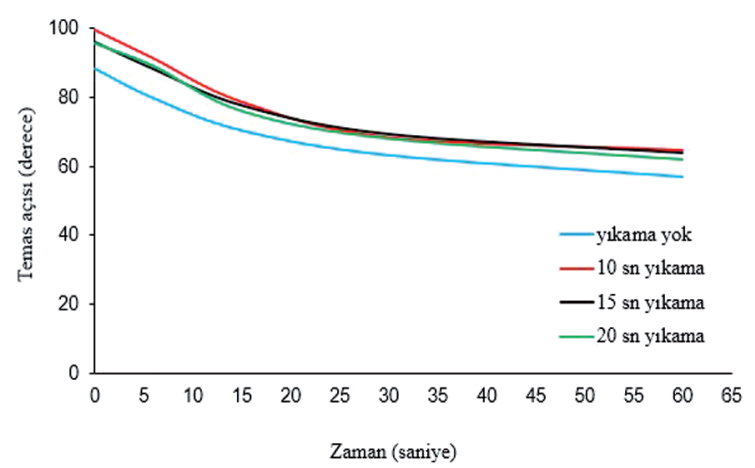

Şekil 5. Polimerizasyonu tamamlanmış EXP ölçü materyalinin yıkama yapılmadan, 10 sn, 15 sn ve 20 sn yıkama sonrası zamana bağlı göstermiş olduğu temas açısı değişimi

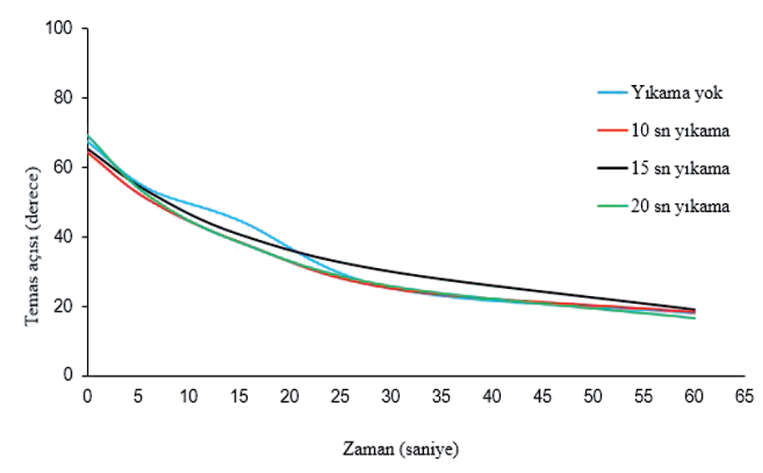

Şekil 6. Polimerizasyonu tamamlanmış IMP ölçü materyalinin yıkama yapılmadan, 10 sn, 15 sn ve 20 sn yıkama sonrası zamana bağlı göstermiş olduğu temas açısı değişimi

yıkama ve 15 sn yıkama grupları değerlendirildiğinde, sadece 60. sn ölçümünde istatistiksel olarak fark bulunduğu gözlendi $(p<0.002)$. On beş sn yıkama ve 20 sn yıkama grupları değerlendirildiğinde, hiçbir ölçüm zamanında istatistiksel fark gözlenmedi ( $p>0.002)$. On sn yıkama ve 20 sn yıkama grupları değerlendirildiğinde başlangıç ölçüm değeri (0 sn) ve son ölçüm değerinde (60 sn) fark gözlenirken ( $p<0.002)$, diğer ölçüm zamanlarında fark gözlenmedi ( $p>0.002)$.

EXP ölçü materyali grubunda, temas açısı değerlerinin yıkama yapılmadığı takdirde, $89.94^{\circ}$ ile başlayıp $57.80^{\circ}$ ile sonlandığı görüldü. Ölçü materyalinin yıkama işlemi ile değişim gösteren temas açısı değerleri Şekil 5’te gösterildi. Bu grupta tüm yıkama sürelerinin, yıkama yapılmayan gruba göre ıslanabilirliğin azalmasına neden olduğu görüldü $(p<0.002)$. On sn yıkama, 15 sn yıkama ve 20 sn yıkama grupları arasında, belirtilen tüm ölçüm zamanlarında istatistiksel olarak fark gözlenmedi ( $p>0.002)$.

IMP ölçü materyali grubunda, temas açısı değerlerinin yıkama yapılmadığı takdirde, $64.72^{\circ}$ ile başlayıp $17.00^{\circ}$ ile sonlandığı görüldü. Ölçü materyalinin yıkama işlemi ile değişim gösteren temas açısı değerleri Şekil 6 'da gösterildi. Belirtilen sürelerin herhangi biri için yıkama yapılmasının, yine belirtilen değerlendirme zamanlarının herhangi biri için istatistiksel farklılığa neden olmadığı gözlendi ( $p>0.002)$.

\section{TARTIŞMA}

Ölçü yüzeyinin alçı bazlı solüsyonlarla ıslanabilirliğinin yüksek olması alçı modelin oluşturulmasında önemlidir. Sürfaktan ilavesi PVS ölçü materyallerinin ıslanabilirlik özelliğini arttırmaktadır. Ancak ölçü yüzeyinden ağız sıvılarının uzaklaştırııması amacıyla yıkama yapıımasının PVS ölçü materyallerinin ıslanabilirlik özelliğini nasıl etkilediği tartışma konusudur. Bu çalışmada, sürfaktan içeren PVS ölçü materyallerinin (PCP ve PIC) Islanabilirlik özelliğinin yıkama yapılmasından ve farklı yıkama sürelerinden etkilendiği gösterilmiştir. Sürfaktan içeren diğer bir PVS ölçü materyali EXP'in ıslanabilirlik özelliğinin ise, yıkama yapılması ile azaldığı ancak farklı yıkama sürelerinden etkilenmediği gösterilmiştir. Polieter ölçü materyali (IMP) ve sürfaktan içermeyen PVS ölçü materyalinin (PCNS) ıslanabilirlik özelliklerinin ise yıkama işleminden ve farklı yıkama sürelerinden etkilenmediği gösterilmiştir. Bu nedenle 'farklı yıkama sürelerinin ölçü materyalinin ıslanabilirliği üzerinde bir etkisi bulunmamaktadır olarak' kurulan hipotez reddedilmiştir.

Yapısal olarak hidrofobik olan PVS ölçü materyallerinin sürfaktan ilavesi ile ıslanabilirliklerinin arttırıldığı bilinmektedir. ${ }^{23} \mathrm{Bu}$ çalışmada da benzer şekilde sürfaktan içeriği dışında kimyasal yapıları benzerlik gösteren PCP ve PCNS ölçü materyallerinin ıslanabilirliklerinin farklı olduğu gösterilmiştir. Çalışmamızda değerlendirilen sürfaktan içeren PVS ölçü materyallerinin tümü, sürfaktan içermeyen PVS ölçü materyaline kıyasla daha düşük temas açısı değerleri göstermektedir. 
Sürfaktanın diffüze olarak materyalin üst yüzeyine ulaştığı ve hidrofilisiteyi arttırdığı düşünülmektedir. ${ }^{15,16}$ Lee ve arkadaşlarına ${ }^{23}$ göre yüzey aktivasyonu için sürfaktanın yapısal hidrofilisitesinden ziyade yüzeydeki yoğunluğu önemlidir. Ancak etki mekanizması ve nerede konumlandığı ile ilgili farklı görüşler mevcuttur. Bazı araştırmacılar, sürfaktanın ölçü materyalinin yüzeyinde bağlı kaldığını ifade ederlerken ${ }^{14,15,23}$ diğerleri sürfaktanın yüzeyle temasta olan Sıvı içerisine serbestleştiğini düşünmektedir. ${ }^{17,24,25}$ Grundke ve arkadaşlarına ${ }^{16}$ göre polimerizasyonu tamamlanan ölçü materyallerinde, sürfaktan hareketi yüksek seviyede gözlenmektedir; bu sayede sürfaktan yüzeyin en dış tabakalarına ulaşarak temas açısını tekrar düşürebilmekte ve su damlacığının sıvı yüzey gerilimini azaltmaktadır. Araştırmacılar bu mekanizmayı, polimerizasyonu tamamlanmış materyalde sürfaktan molekülleri ile polimer zincirleri arasındaki bağın, polimerize olmamış sistemlere göre daha zayıf olması ve böylece sürfaktan moleküllerinin ara yüze çok daha kolay yönelebilmesi ile açıklamaktadır. ${ }^{16}$ Balkenhol ve ark. ${ }^{25}$ sürfaktanın temasta olan sıvının yüzey gerilimini azalttığını ve PVS'nin yüzey özelliklerini değiştirmediğini göstermişlerdir. Yapmış olduğumuz bu çalışmanın sonuçlarına göre PVS ölçü materyallerinin yıkama sonucu azalan ıslanabilirlik değerlerinin, yüzeyden sürfaktanın uzaklaştığının göstergesi olduğu düşünülmektedir. Benzer şekilde Kanehira ve ark. ${ }^{17}$ PVS ve polieter ölçü materyallerini değerlendirdikleri çalışmalarında; 10 sn yıkama sonrası ve 24 saati takiben yapılan ikinci 10 saniyelik yıkama sonrası PVS ölçü materyallerinde ıslanabilirliğin yıkama yapılmayan duruma göre azaldığını göstermişlerdir.

Çalışmamızda yapısal olarak hidrofilik olan polieter ölçü materyalinin ıslanabilirlik değerlerinin yıkamadan ve farkı yıkama sürelerinden etkilenmediği gösterilmiştir. Bu bulgular Kanehira ve arkadaşlarının ${ }^{17}$ yaptıkları çalışma sonuçları ile benzerlik göstermektedir.

$\mathrm{Bu}$ in vitro çalışmada ölçü materyallerinin yüzeyinin temizlenmesi taklit edilirken temiz ölçü yüzeyleri yıkanmış ve kan, tükürük gibi ağız sıvıları göz ardı edilmiştir. Ayrıca yıkama sonrası temas açısı ölçümünde kullanılan sıvının analizi gelecek çalışmalarda değerlendirilebilir.

\section{Sonuç}

$\mathrm{Bu}$ in vitro çalışmanın sınırlandırmaları dahilinde, çalışmamızda değerlendirilen sürfaktan içeren polivinilsiloksan ölçü materyallerinin, su ile yıkanma işlemi ıslanabilirlik özelliklerinin azalmasına neden olabilmektedir. Çalışmamızda değerlendirilen polieter ölçü materyalinin ıslanabilirlik özelliği yıkama işleminden etkilenmemektedir.

Çıkar çatışması: Yazarlar bu çalışmayla ilgili herhangi bir çıkar çatışmalarının bulunmadığını bildirmişlerdir.

\section{KAYNAKLAR}

1. Vassilakos N, Fernandes CP. Surface properties of elastomeric impression materials. J Dent 1993;21:297-301.

2. McCormick JT, Antony SJ, Dial ML, Duncanson MG Jr, Shillingburg HT Jr. Wettability of elastomeric impression materials: effect of selected surfactants. Int J Prosthodont 1989;2:413-20.

3. O'Brein WJ. Dental materials and their selection, 4th edn. Illinois: Quintessence Publishing Co Inc; 2008.

4. Anusavice KJ. Phillips' science of dental materials, 11th edn. St. Louis: Elsevier Mosby; 2003.

5. Rosenstiel SF, Land MF, Fulimoto J. Contemporary fixed prosthodontics, 4th edn. St. Louis: Mosby; 2006.

6. Rupp F, Axmann D, Jacobi A, Groten M, Geis-Gerstorfer J. Hydrophilicity of elastomeric non-aqueous impression materials during setting. Dent Mater 2005;21:94-102.

7. Kess RS, Combe EC, Sparks BS. Effect of surface treatments on the wettability of vinyl polysiloxane impression materials. J Prosthet Dent 2000;84:98-102

8. Soh G, Chong YH. Relationship between critical convergence angle and surface defects in stone casts. Quintessence Int 1990;21:675-9.

9. Pratten $\mathrm{DH}$, Craig RG. Wettability of a hydrophilic addition silicone impression material. J Prosthet Dent 1989;61:197-202.

10. al-Omari WM, Jones JC, Wood DJ. The effect of disinfecting alginate and addition- cured silicone rubber impression materials on the physical properties of impressions and resultant casts. Eur J Prosthodont Restor Dent 1998;6:103-10.

11. Mandikos MN. Polyvinyl siloxane impression materials: an update on clinical use. Aust Dent J 1998;43:428-34.

12. Panichuttra R, Jones RM, Goodacre C, Munoz CA, Moore BK. Hydrophilic poly(vinyl siloxane) impression materials: dimensional accuracy, wettability, and effect on gypsum hardness. Int J Prosthodont 1991;4:240-8.

13. Chai JY, Yeung TC. Wettability of nonaqueous elastomeric impression materials. Int J Prosthodont 1991;4:555-60.

14. Norling BK, Reisbick MH. The effect of nonionic surfactants on bubble entrapment in elastomeric impression materials. J Prosthet Dent 1979;42:342-7.

15. Oh YI, Lee DY, Hwang SY, Kim KN, Kim KM. Effect of non-ionic surfactants on surface properties of hydrophilic polyvinyl siloxane impression materials. Colloids Surf A-Physicochem Eng Aspects 2003;229:9-17.

16. Grundke K, Michel S, Knispel G, Grundler A. Wettability of silicone and polyether impression materials: Characterization by surface tension and contact angle measurements. Colloids Surf A-Physicochem Eng Aspects 2008;317:598-609.

17. Kanehira M, Finger WJ, Komatsu M. Surface detail reproduction with new elastomeric dental impression materials. Quintessence Int 2007;38:479-88.

18. Milward PJ, Waters MG. The effect of disinfection and a wetting agent on the wettability of addition-polymerized silicone impression materials. J Prosthet Dent 2001;86:165-7.

19. Shetty SR, Kamat G, Shetty R. Wetting characteristics of addition silicon materials subjected to immersion disinfection: an in-vitro study. Eur J Prosthodont Restor Dent 2013;21:98-104.

20. Choi YR, Kim KN, Kim KM. The disinfection of impression materials by using microwave irradiation and hydrogen peroxide. J Prosthet Dent 2014;112:981-7.

21. Goel K, Gupta R, Solanki J, Nayak M. A comparative study between microwave irradiation and sodium hypochlorite chemical disinfection: a prosthodontic view. J Clin Diagn Res 2014;8:ZC42-6.

22. Meghashri K, Kumar P, Prasad DK, Hegde R. Evaluation and comparison of high-level microwave oven disinfection with chemical disinfection of dental gypsum casts. J Int Oral Health 2014;6:56-60.

23. Lee DY, Oh YI, Chung KH, Kim KM, Kim KN. Mechanism study on surface activation of surfactant-modified polyvinyl siloxane impression materials. J Appl Poly Sci 2004;92:2395-401.

24. Takahashi H, Finger WJ. Dentin surface reproduction with hydrophilic and hydrophobic impression materials. Dent Mater 1991;7:197-201.

25. Balkenhol M, Haunschild S, Lochnit G, Wöstmann B. Surfactant release from hydrophilized vinylpolysiloxanes. J Dent Res 2009;88:668-72. 


\section{The effect of rinsing time periods on wettability of elastomeric impression materials: in vitro study}

\author{
Abstract \\ OBJective: The aim of this study was to determine whether \\ different rinsing time periods affected the wettability of \\ polymerized elastomeric impression materials. \\ Materials And Method: Panasil Contact Plus (PCP), Panasil \\ Contact Non-Surfactant (PCNS), Panasil Initial Contact \\ (PIC), Express (EXP) and Impregum (IMP) impression ma- \\ terials were tested. Standardized samples were rinsed with \\ water for $10 \mathrm{~s}, 15 \mathrm{~s}$ or $20 \mathrm{~s}$, and the wettability was deter- \\ mined by contact angle measurement through an evalua- \\ tion period of 60 seconds $(n=7)$. Non-rinsed groups were
}

used as control. Measurements were made at 5 time points (at $0,6,15,30$ and 60 seconds). Kruskal Wallis test and Conover's multiple comparison tests were used for all multiple comparisons. Bonferroni adjustment was applied for controlling Type I error $(p<0.002)$.

REsULts: Rinsing 10 s, 15 s or 20 s significantly reduced the wettability of the impression materials PCP, PIC and $\operatorname{EXP}(p<0.002)$. However, wettability of the impression materials PCNS and IMP did not significantly change after rinsing ( $p>0.002)$.

Conclusion: Rinsing the surfactant-containing polyvinylsiloxane impression materials decreased their wettability, whereas no such effect was seen for the surfactant free polyvinylsiloxane and polyether impression materials.

KEYWORDS: Dental impression materials; polymerization; wettability 